This synopsis is based on a report entitled 'De invloed van tuinturf, $p H, M g$ and beregening op de groei van calluna and erica' by H. Niers, Report 11-84, Instituut voor Bodemvruchtbaarheid, Haren (Gr.), Netherlands, 1984.87 pp., 9 figs., 20 tables, 18 refs., 11 appendices. Dutch with English summary and captions.

Available as paper copy (order R046P, available free) or microfiche (order R046M, f 12.50 including postage) at: NARD, clo Pudoc, P.O. Box 4, 6700 AA Wageningen, Netherlands (telex 45015 blhwg).

\title{
A study of soil variation in podzols in the Netherlands
}

\author{
M. J. M. Hootsmans and M. F. Wallis de Vries (Department of Soil Science, Agri- \\ cultural University, P.O. Box 37,6700 AA Wageningen, Netherlands)
}

Received 17 June 1985; accepted 8 August 1985

\begin{abstract}
Variation of 31 soil characteristics was studied in a 100-ha area with a nested random sampling method and a 400-m transect. Apart from water-table, no characteristics or combinations thereof could be mapped accurately with a sampling distance of $50 \mathrm{~m}$. Wet and dry podzols were distinguished, distributed in a fine-grained pattern of small units (less than $4 \mathrm{~m}^{2}$ ).

Key words: soil variation, soil mapping, nested sampling, podzols.

Introduction. A well-known problem encountered in soil mapping is the necessity to delineate soil types while the boundary between regions is only vague. One soil type usually dominates in each region, buth when short-distance variation is large, a region has to be described by soil type complexes. The problem of discerning boundaries becomes more difficult when the desired amount of detail on the soil map increases, as this usually coincides with an increase in vagueness of the boundaries. When the relation between sampling distance and the accuracy of the resulting soil map is known, it is possible to choose a sampling distance which is optimal in view of both the purpose of the soil map and the actual variation in the area. Without this information, the usefulness of the soil map remains unknown.

To investigate the possibilities for a detailed soil map in a 100-ha area in the province of Brabant in the south of the Netherlands, we made a study of soil variation. The area is a more or less undisturbed complex of moor and fens, dominated by dry and wet podzols, developed in Pleistocene cover sand.
\end{abstract}


Material and methods. The relation between the distance between two points and their expected difference in characteristics was determined with a nested random sampling method and analysed with a nested analysis of variance (Sokal \& Rohlf, 1981). This method, tested by Burrough et al. (1983) for soil mapping purposes, provides a way to determine the relative contributions of the variance at different sampling distances to the total variance of a soil characteristic in an area.

Eight clusters of 9 sampling points were distributed randomly over the area. Each cluster was constructed as follows. Starting at a main point, a second point was selected at a distance of $50 \mathrm{~m}$. Each of both points was connected with a point at 20 $\mathrm{m}$ distance. Adjacent to each of these four points a point was selected at $2 \mathrm{~m}$. Final$\mathrm{ly}$, a point at $100 \mathrm{~m}$ distance from the main point was selected. Each cluster thus contributed four times to the estimate of variation over $2 \mathrm{~m}$, twice to the estimate over $20 \mathrm{~m}$ and once to the estimates over 50 and $100 \mathrm{~m}$.

A 400-m transect was sampled at 2-m intervals to reconstruct a nearly continuous picture of short distance variation. Both in the nested sampling analysis and the transect analysis, the soil was sampled to a depth of $120 \mathrm{~cm}$. We distinguished 31 characteristics, among which depth and thickness of soil horizons, colour, texture, water-table and mottling. Combinations of characteristics were made by principal component analysis. Soil samples from different depths at distinct transitions in elevation and vegetation along the transect were analysed for organic matter content (loss on ignition), $\mathrm{pH}$ and iron content (colour intensity after ignition).

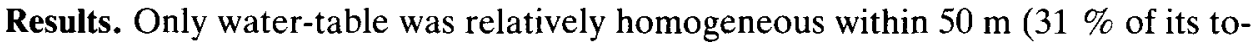
tal variance). All other characteristics had far more than $50 \%$ of their total variance within this distance. For 19 characteristics, $50 \%$ of total variance occurred within $2 \mathrm{~m}$. Standard deviation of many characteristics was less than $25 \%$ of their mean. So, none of the characteristics except water-table could be mapped accurately with a 50-m sampling distance. The random sampling method happened to result in an underrepresentation of the drier parts of the area.

Principal component analysis of the transect data and of the nested sampling data gave the same combinations of characteristics which were related with elevation and hydrology. However, none of the combinations could be used for mapping either: all had more than $50 \%$ of their total variance within $2 \mathrm{~m}$. Wet and dry podzols could be distinguished, but although much variation within these types remained, no further division was possible. Wet podzols differed from dry podzols by their lower elevation, a brown instead of black $\mathrm{B}$ horizon and the absence of a $\mathrm{C}$ horizon within $120 \mathrm{~cm}$. Wet podzols had a lower $\mathrm{pH}$ (both $\mathrm{CaCl}_{2}$ and $\mathrm{H}_{2} \mathrm{O}$ ), less iron, a higher organic matter content of the eluvial horizon and a lower organic matter content of the B horizon than dry podzols. In Fig. 1, a large part of the transect is shown.

Conclusions. Nested sampling analysis indicated that the two soil types distinguished occur in a fine-grained pattern of small units (less than $4 \mathrm{~m}^{2}$ ), although the area seemed clearly divided in wet and dry regions. A systematic distribution of randomly constructed clusters, with the soil surveyors' experience as a source of extra in- 


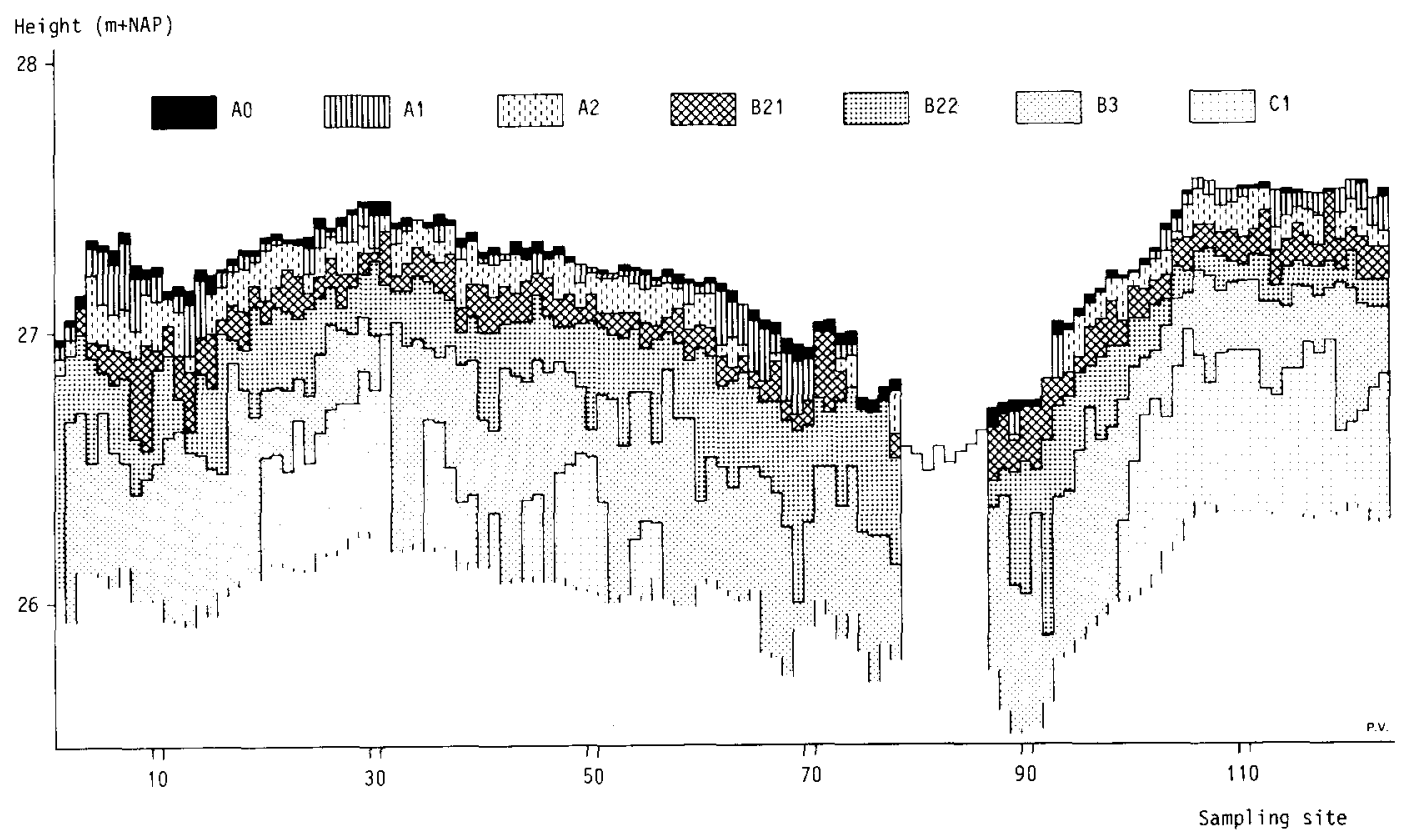

Fig. 1. Part of the $400 \mathrm{~m}$-transect. NAP, Normaal Amsterdams Peil (mean sea level).

formation, may be a solution for this problem. The results suggest that the accuracy of large-scale soil maps may be less than their scale seems to indicate.

\section{References}

Burrough, P. A., G. Oerlemans, G. Stoffelen \& J. V. Witter, 1983. Reconnaissance soil studies to determine optimum survey scales and mapping legend for soil moisture research in the Hupselse Beek hydrological catchment; Oost Gelderland. Report No 1, 'Study Group Soil Variability Hupselse Beek', Wageningen, $47 \mathrm{pp}$.

Sokal, R. R. \& F. J. Rohlf, 1981. Biometry. Freeman and Co., San Fancisco, 859 pp.

This synopsis is based on an undergraduate research report entitled 'Een analyse van de bodemvariatie in een natuurgebied bij Valkenswaard: De Hasselsvennen' by Michiel Hootsmans and Michiel Wallis de Vries, Department of Soil Science and Geology, Agricultural University, Wageningen, 1985. 56 pp., 20 figs., 13 tables, 16 refs., 5 appendices. Dutch, English summary.

Available as paper copy (order R047P, $f 20$ including postage) or microfiche (order R047M, f 12.50 including postage) at: NARD, clo Pudoc, P.O. Box 4, 6700 AA Wageningen, Netherlands (telex 45015 blhwg). 